7th International Symposium on Superalloy 718 and Derivatives Edited by: E.A. Ott, J.R. Groh, A. Banik, I. Dempster, T.P. Gabb, R. Helmink, X. Liu, A. Mitchell, G.P. Sjöberg, and A. Wusatowska-Sarnek TMS (The Minerals, Metals \& Materials Society), 2010

\title{
Effect of Microstructure on the High Temperature Fatigue Properties of Two Ni-based Superalloys
}

G. Muralidharan ${ }^{1}$, Rick Battiste ${ }^{1}$, Edward A. Kenik ${ }^{1}$, James Bentley ${ }^{1}$, and Bruce G. Bunting ${ }^{2}$

\author{
${ }^{1}$ Materials Science and Technology Division \\ ${ }^{2}$ Energy and Transportation Sciences Division \\ Oak Ridge National Laboratory \\ 1 Bethel Valley Road, Oak Ridge, TN-37831
}

Notice: This manuscript has been authored by UT-Battelle, LLC, under Contract No. DE-AC0500OR22725 with the U.S. Department of Energy. The United States Government retains and the publisher, by accepting the article for publication, acknowledges that the United States Government retains a non-exclusive, paid-up, irrevocable, world-wide license to publish or reproduce the published form of this manuscript, or allow others to do so, for United States Government purposes.

Keywords: VHCF, exhaust valves, precipitation strengthening

\begin{abstract}
There is significant need for Ni-based superalloys in the next generation automotive engine components such as exhaust valves. High temperature, high cycle fatigue life is one of the important properties required for such applications. The focus of this work is to evaluate the effect of microstructure on the high cycle fatigue properties of two Ni-based alloys, alloy 751, an alloy used in these applications at lower temperatures, and Waspaloy. High cycle fatigue lives of the alloys were evaluated using in-situ high temperature fully reversed fatigue tests at $870^{\circ} \mathrm{C}$ and a nominal frequency of $30 \mathrm{~Hz}$. Scanning electron microscopy and transmission electron microscopy were used to characterize the microstructure of the alloys. Computational modeling was used to calculate the equilibrium microstructure and microstructural coarsening at $870^{\circ} \mathrm{C}$. Correlation of fatigue properties with microstructure of the alloys shows that for the experimental conditions used in the study, the fatigue life of Waspaloy, which has greater high temperature strength and larger $\gamma^{\prime}$ volume fraction, is better than that of alloy 751 .
\end{abstract}

\section{Introduction}

There has been a significant interest in recent years in understanding the fatigue performance of materials in the Very High Cycle Fatigue (VHCF) range or Ultrahigh-cycle fatigue range (UHCF) with typical lifetimes greater than $10^{7}$ cycles. In this range of lifetimes, it has been emphasized that fatigue crack initiation becomes much more important than crack propagation [1]. Fatigue failures have been observed at stresses below the conventional high cycle fatigue limit, resulting in significant motivation to understand the microstructural origins of such failures $[1,2]$. The role of microstructural characteristics on crack initiation in the VHCF regime has been studied in a wide range of materials, including polycrystal and single crystal Ni-based superalloys [1-3].

Very high cycle fatigue life at high temperatures is an important property for automotive components such as exhaust valves. With the demand for increased thermal efficiencies in engines, there is a need for materials to withstand higher operating temperatures and pressures 
while providing satisfactory fatigue life. In addition to bulk microstructural characteristics the role of surface oxides also has to be considered in evaluating the high temperature fatigue life of alloys [4]. The purpose of this study is to evaluate the high temperature very high cycle fatigue life and the role of microstructure on the life of two common Ni-bases superalloys, alloy 751 and Waspaloy.

\section{Experimental Methods}

Commercially available Waspaloy was obtained in the form of round bars of diameter 0.635 ” in the annealed condition and subjected to a two-step heat-treatment consisting of $840^{\circ} \mathrm{C} / 4 \mathrm{hrs} /$ air cool followed by a $760^{\circ} \mathrm{C} / 16 \mathrm{hrs} /$ air cool in sealed quartz tubes. Alloy 751 heat-treated using a multi-step heat-treatment process with final aging performed at $780^{\circ} \mathrm{C}$ was obtained from an industrial partner in the form of round bars $0.875^{\prime}$ diameter. Table 1 shows the major elemental compositions of the two alloys used in the study. Typical mechanical properties of alloy 751 at $871^{\circ} \mathrm{C}$ are yield strength of about $352 \mathrm{MPa}$ and a tensile strength of about $394 \mathrm{MPa}$ whereas that of Waspaloy are yield strength of about $572 \mathrm{MPa}$ and a tensile strength of about $580 \mathrm{MPa}$.

Table 1. Nominal composition (wt. \%) of the two alloys used in the study

\begin{tabular}{|c|c|c|c|c|c|c|c|c|c|c|c|c|c|c|}
\hline Alloy & $\mathrm{C}$ & $\mathrm{Mn}$ & $\mathrm{Si}$ & $\mathrm{Cu}$ & $\mathrm{Cr}$ & $\mathrm{Mo}$ & $\mathrm{Co}$ & $\mathrm{Al}$ & $\mathrm{Ti}$ & $\mathrm{Fe}$ & $\mathrm{Nb}$ & $\mathrm{V}$ & $\mathrm{Zr}$ & $\mathrm{Ni}$ \\
\hline Alloy 751 & 0.04 & 0.04 & 0.08 & 0.04 & 16 & 0.01 & 0.03 & 1.2 & 2.3 & 8.2 & 0.9 & 0.1 & - & Bal. \\
\hline Waspaloy & 0.03 & 0.03 & 0.03 & 0.02 & 19.3 & 4.2 & 12.5 & 1.3 & 3.0 & 1.6 & - & - & 0.05 & Bal. \\
\hline
\end{tabular}

In-situ high temperature uniaxial fatigue tests were conducted in a servohydraulic test machine, rated at 50 kip maximum load for the frame, and with a 20 kip actuator. Grips were aligned to less than \pm 0.001 to ensure both concentricity and angularity. A three zone temperature controlled furnace system with resistance heaters was used to heat the specimens. Heat up was achieved in about 45 minutes and heat soak of 30 minutes was used before test initiation. Temperature was controlled at $870^{\circ} \mathrm{C} \pm 3^{\circ} \mathrm{C}$ using wire wrapped type-K thermocouples with the ASTM wire wrapped attachment method. All tests were conducted in air. The 407 internal function generator was used to achieve loading waveform and speed (Sine and $30 \mathrm{~Hz}$ ). Amplitude control was activated in less than 30 seconds after test initiation. Interlocks on the 407 detected specimen failure (rapid stroke movement) and shut down the test, thus determining the cycles to failure. Figure 1 shows a schematic of the specimens used in the study.

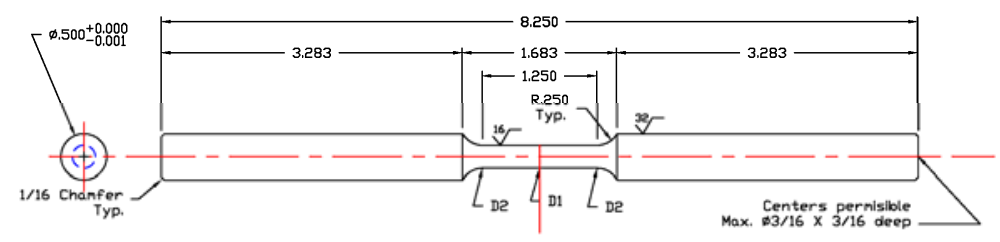

Figure 1. Schematic of specimens used for in-situ high temperature, uniaxial fatigue tests

Microstructural characterization was performed on material obtained from the gage length of the mechanical test specimens. Optical, scanning and transmission electron microscopy were used to characterize the microstructure of the specimens over different length scales. Secondary (SE) and back-scattered electron images (BSE) were used to characterize volume fraction, size and morphology of $\gamma^{\prime}$ precipitates. Transmission Electron Microscope (TEM) images were obtained 
by orienting the specimens to the [001] zone axis. TEM images were obtained from regions representative of the microstructure but with lower dislocation densities. Quantitative image analysis using Image Pro was used to characterize the area fraction of $\gamma^{\prime}$ and the average size of $\gamma^{\prime}$ in a plane section. Average particle size in the TEM images from obtained from the manual measurement of the individual particle sizes in the TEM images using Image Pro.

\section{Results}

Figures 2 (a) and 2 (b) show the phase equilibria predictions from equilibrium thermodynamic calculations as a function of temperature obtained using JMatPro v 4.1 [5] and Ni-database [6] for the compositions of the two alloys shown in Table I. Calculations show that $\gamma^{\prime}$ is the dominant second phase which acts as the major strengthening phase in both alloys. Additionally $\mathrm{MC}$ and $\mathrm{M}_{23} \mathrm{C}_{6}$ type carbides are present in both alloys. An analysis of the phases present at $870^{\circ} \mathrm{C}$ shows that the equilibrium $\gamma^{\prime}$ content in Waspaloy is about $16.7 \mathrm{wt}$. \%, being greater than that of Alloy 751 for which the $\gamma^{\prime}$ content was calculated to be 7.7 wt. \%. Calculated coarsening rate of $\gamma^{\prime}$ precipitates in alloy 751 is $26.6 \mathrm{~nm} / \mathrm{h}^{1 / 3}$ greater than that of Waspaloy (about 25 $\mathrm{nm} / \mathrm{h}^{1 / 3}$ ) at the temperature of interest.

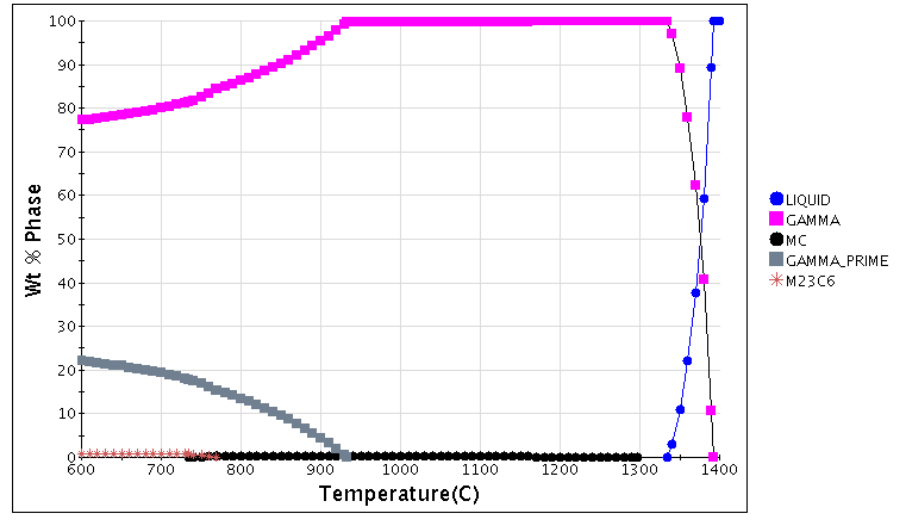

(a)

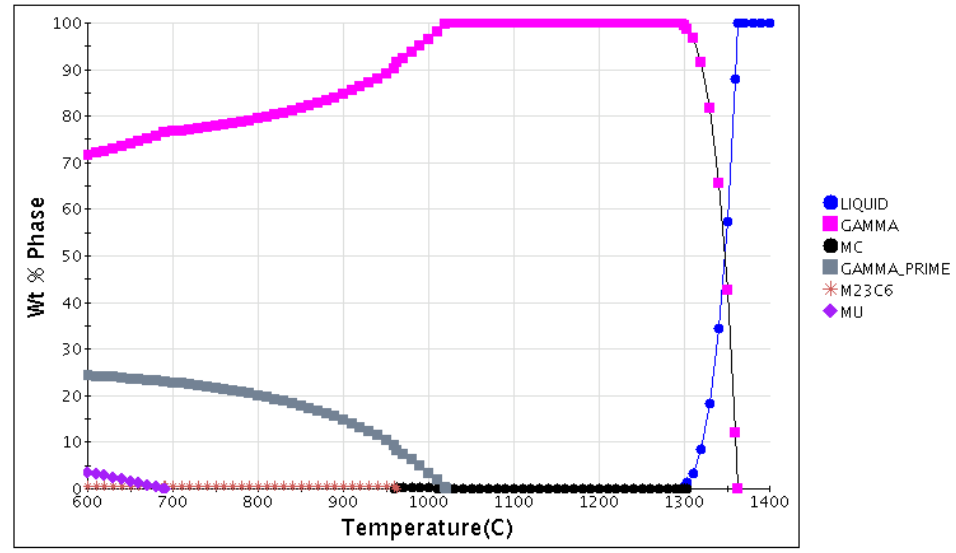

(b)

Figure 2. Results of thermodynamic calculations showing effect of temperature on the phases present in equilibrium as a function of temperature in (a) alloy 751 and (b) Waspaloy. Note that the predicted amounts of $\gamma^{\prime}$ precipitates is larger in Waspaloy. 
Figures 3 (a) and (b) show optical images obtained from alloy 751 and Waspaloy in the aged condition. Note that the average grain size of alloy 751 is smaller than that of Waspaloy. Presence of a mixture of large grains and small grains indicating some abnormal grain growth can be observed in the Waspaloy specimen, consistent with previous observations [7].

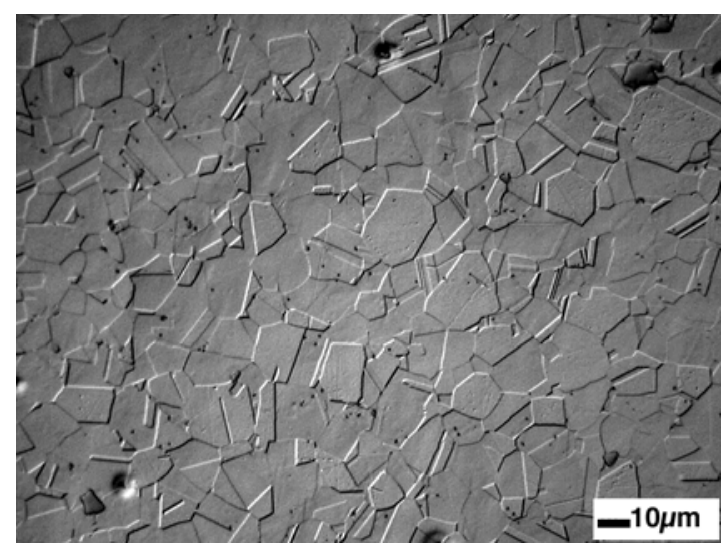

(a)

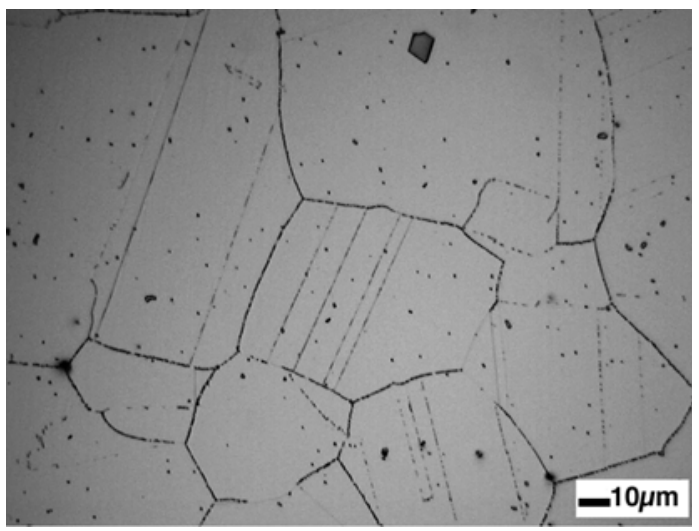

(b)

Figure 3. Optical micrograph showing microstructure of (a) Alloy 751, and (b) Waspaloy in the aged condition. Grain size of Waspaloy specimens used in the current study is larger than the grain size in 751 specimens along with some evidence of abnormal grain growth.

Figure 4 (a) shows a cross-sectional SEM image obtained from the gage length region of an alloy 751 specimen that failed after about $3.9 \times 10^{6}$ cycles $\left(36.6\right.$ hours of exposure at $870^{\circ} \mathrm{C}$ ). Image analysis shows that the volume fraction (equal to the area fraction) of $\gamma^{\prime}$ in this condition was about $6.3 \%$ with the average size measured from the image of about $64 \mathrm{~nm}$. Figure 4 (b) shows a TEM image obtained from the gage length of another specimen from alloy 751 that failed after $19 \times 10^{6}$ cycles ( 177 hours). Analysis of the TEM image shows the presence of particles with an average size of about $151 \mathrm{~nm}$, indicating significant coarsening of $\gamma^{\prime}$ during the longer duration of the fatigue test. Figure 5 (a) shows an SEM image obtained from the gage length region of a Waspaloy specimen that failed after $2.3 \times 10^{6}$ cycles $\left(22\right.$ hours of exposure at $\left.870^{\circ} \mathrm{C}\right)$. Analyses of SEM images show that the volume fraction of $\gamma^{\prime}$ in this condition was about $17.1 \%$. Figure 5 (b) shows a TEM image obtained from the gage length of another specimen alloy Waspaloy specimen that failed after about $55 \times 10^{6}$ cycles (512 hours) which shows an average 
size of $198 \mathrm{~nm}$. Comparison of the TEM images obtained from alloy 751 and Waspaloy specimens (figures 4(b) and 5 (b)) shows that the $\gamma^{\prime}$ precipitates in alloy 751 evolves to be cuboidal in shape while the $\gamma^{\prime}$ in Waspaloy is spherical/ellipsoidal consistent with the larger magnitude of $\gamma-\gamma^{\prime}$ misfit (defined as $2\left(\mathrm{a}_{\gamma},-\mathrm{a}_{\gamma}\right) / \mathrm{a}_{\gamma^{\prime}}+\mathrm{a}_{\gamma}$ ) in alloy 751 calculated using JMatPro to be $0.44 \%$ compared to that of Waspaloy calculated to be about $0.14 \%$.

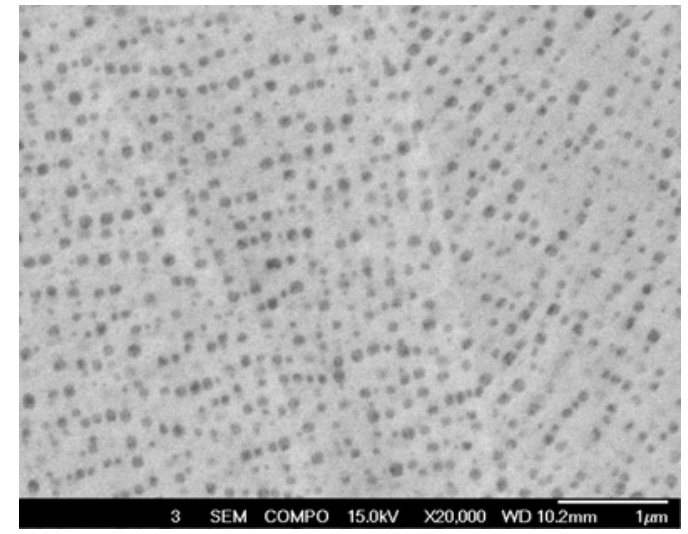

(a)

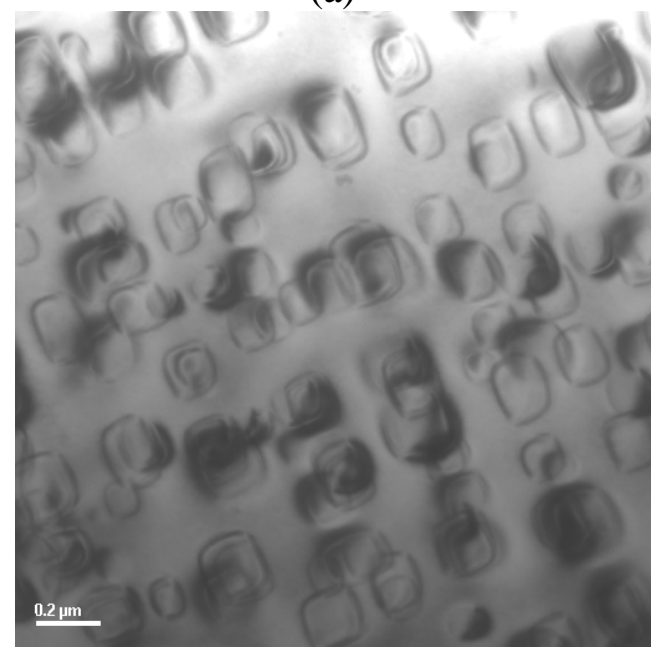

(b)

Figure 4 (a). Back-scattered SEM image showing $\gamma^{\prime}$ particles in the gage length region of an alloy 751 specimen that failed after about $3.9 \times 10^{6}$ cycles (36.6 hours of exposure at $870^{\circ} \mathrm{C}$ ) at a stress level amplitude of $150 \mathrm{MPa}$. (b) Transmission Electron Microscope image of cuboidal $\gamma^{\prime}$ particles in the gage length region of an alloy 751 specimen that failed after about $19 \times 10^{6}$ cycles ( 177 hours) at $870^{\circ} \mathrm{C}$ and a stress amplitude of $100 \mathrm{MPa}$.

Figure 6 shows the variation in microhardness values as a function of cycles and exposure time in alloy 751 and in Waspaloy, measured in metallographic samples obtained from the gage length of the fatigue tested specimens. It is important to note that the initial microhardness values and the microhardness values after identical exposure times at $870^{\circ} \mathrm{C}$ are greater for Waspaloy specimens. It is also interesting to note that a significant decrease in microhardness values for both alloys occur in the very early stages of exposure at $870^{\circ} \mathrm{C}$. This can be related to the fact that aging treatments of the alloys were performed at temperatures lower than $870^{\circ} \mathrm{C}$. Since the equilibrium volume fraction of $\gamma$ ' decreases with an increase in temperature, the volume fraction 
of $\gamma^{\prime}$ decreases rapidly in the early stages of exposure at $870^{\circ} \mathrm{C}$ along with an increase in the size of the $\gamma^{\prime}$ precipitates, resulting in the decrease in the microhardness values.

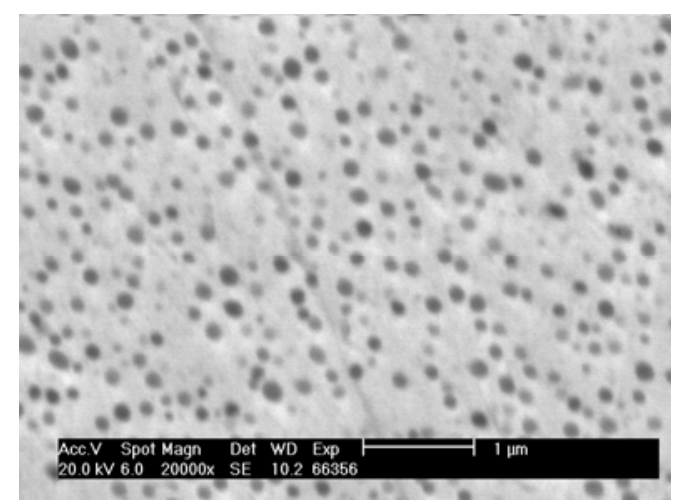

(a)

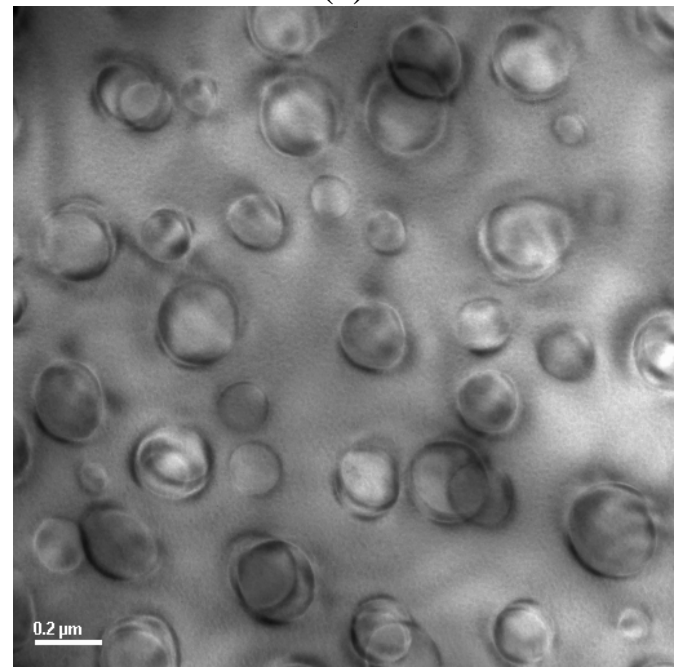

(b)

Figure 5 (a). Secondary electron (SE) image showing $\gamma^{\prime}$ particles in the gage length region of an Waspaloy specimen that failed after about $2.3 \times 10^{6}$ cycles (22 hours of exposure at $870^{\circ} \mathrm{C}$ ) and a stress amplitude of $275 \mathrm{MPa}$. (b) TEM of $\gamma^{\prime}$ particles in the gage length region of a Waspaloy specimen that failed after about $55 \times 10^{6}$ cycles $(\sim 512$ hours $)$ at $870^{\circ} \mathrm{C}$ and a stress amplitude of $200 \mathrm{MPa}$.

Figure 7 shows the fatigue lives of alloy 751 and Waspaloy as a function of the stress obtained using fully reversed uniaxial fatigue tests. The range of stress amplitudes selected for the study was determined by the typical in-service stresses experienced by the component. Several observations should be highlighted with the data presented in figure 7. First, it should be noted that even for the lowest stresses at the temperature of interest, failure was observed within a finite number of cycles $\left(<10^{8}\right.$ cycles). Furthermore, note that at all stress levels used in this study, for a given stress amplitude, the cycles to failure of Waspaloy is greater than that of alloy 751. 


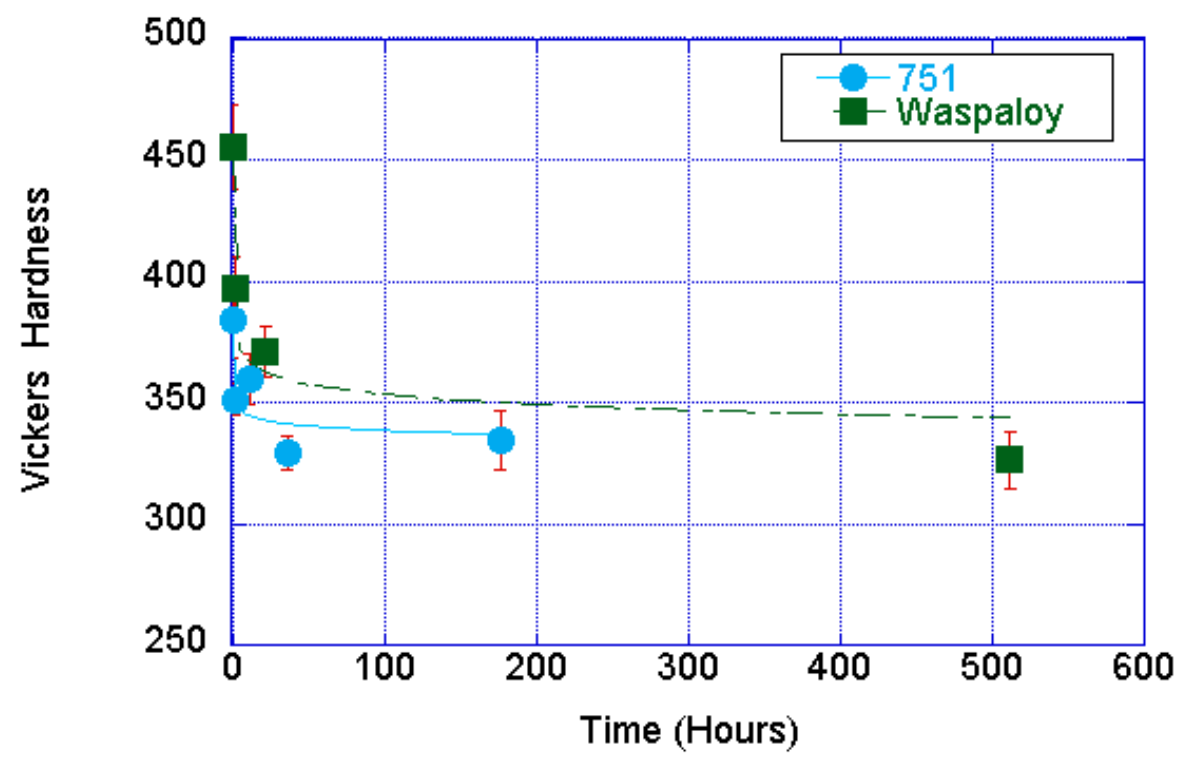

Figure 6. Effect of exposure time at $870^{\circ} \mathrm{C}$ during testing on the microhardness in 751 and Waspaloy specimens.

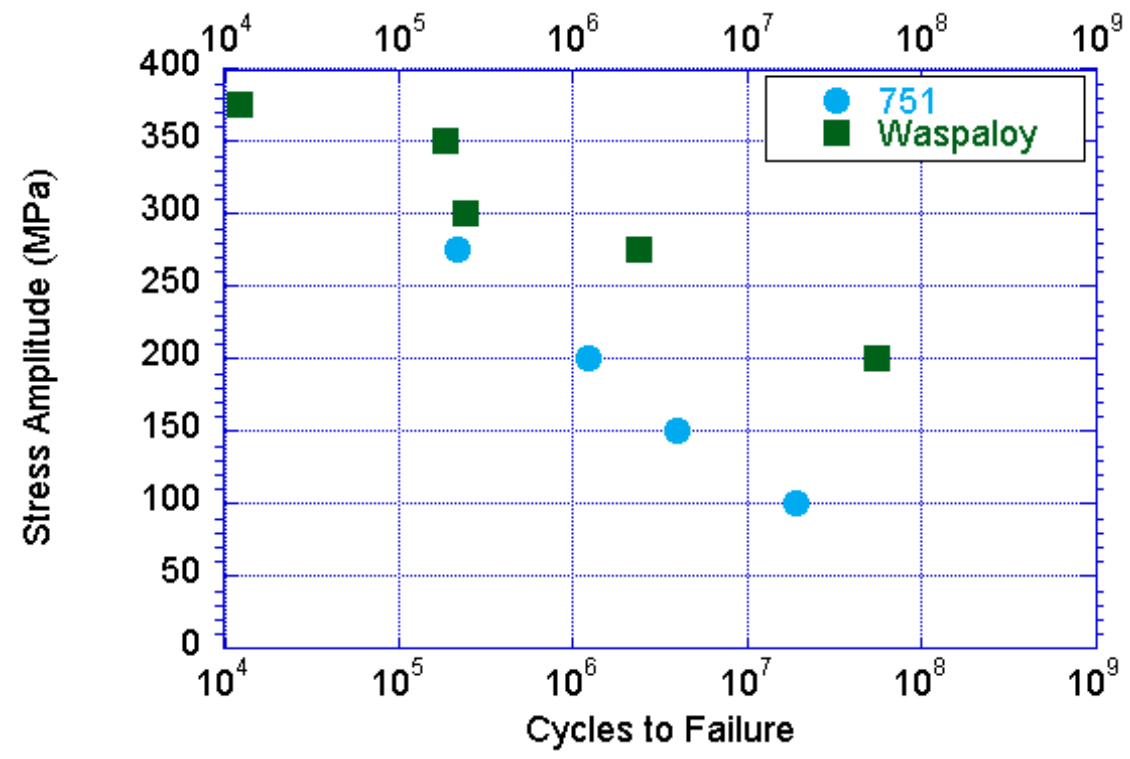

Figure 7. Uniaxial fatigue tests $(\mathrm{R}=-1)$ conducted on Waspaloy at $870^{\circ} \mathrm{C}$ show greater fatigue lives compared to fatigue lives observed in alloy 751 specimens at the same levels of stress amplitude.

\section{Discussion}

As mentioned earlier, in the high cycle fatigue regime, crack initiation, rather than crack propagation constitutes the major component of the fatigue life. A number of microstructural 
features may act as potential sites for crack nucleation [3, 8-10]. Previous work on Ni-based alloys show that defects such as inclusions and pores can result in the initiation of fatigue cracks [3]. In relatively clean, wrought materials, this initiation is likely to play a smaller role. Slip processes play an important role in the initiation of fatigue cracks. Fatigue cracks can be initiated by the intrusion-extrusion mechanism from persistent slip bands that form due to localized slip on the active slip planes. Most of the slip band cracks occur in surface grains that are favorably oriented for slip with a Schmid factor of 0.5 in Ni-based alloys. It has been observed that coarse grained materials are more prone to slip band cracks than fine-grained materials [3, 9]. In addition, crack initiation can occur at twin and grain boundaries as a result of slip impingement. Fatigue cracks can initiate at grain or twin boundaries where impinging slip causes plastic incompatibility and stress concentration. For example, in Waspaloy, it has been shown that the initiation site is located in a cluster of grains with grain misorientations less than $15^{\circ}$ and exhibiting similar Schmid factors [3, 10]. The "supergrain" acts as a single grain allowing easy slip transmission across low-angle boundaries, with an effective slip distance that is larger than the average grain size.

In a study of the very high cycle fatigue life of Nimonic 75, a solid solution strengthened alloy and Nimonic 80A, a $\gamma^{\prime}$ strengthened alloy, it was observed that the Nimonic 80A showed better fatigue life in the peak-aged condition when compared to Nimonic 75 [11]. Fatigue tests on plastically deformed and undeformed peak-aged Nimonic 80A specimens, showed that the effect of surface roughening due to predeformation on the high cycle fatigue life diminished at temperatures greater than $600^{\circ} \mathrm{C}$ due to the rapid formation of oxide layers at the higher temperatures [12]. It was found that independent of the pretreatment, the fatigue life obtained at $800^{\circ} \mathrm{C}$ was lower than that of the fatigue life from RT $-600^{\circ} \mathrm{C}$. This was attributed to the formation of a thicker, brittle oxide film leading to earlier crack initiation and the loss of static strength.

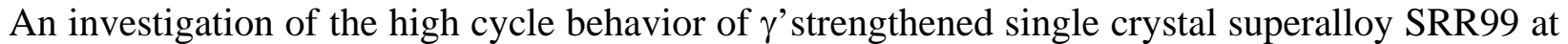
temperatures of $700^{\circ} \mathrm{C}, 760^{\circ} \mathrm{C}, 850^{\circ} \mathrm{C}$, and $900^{\circ} \mathrm{C}$ showed that the temperature dependence of the high cycle fatigue life correlated well with the temperature dependence of the static strengths of the alloy [13]. Our observation on the improved fatigue life of Waspaloy when compared to alloy 751 is consistent with the larger high temperature static strength of Waspaloy and the above observations in Nimonic 80A and SRR99. It can be concluded that despite the larger grain size in Waspaloy, the differences in localized slip activity in Waspaloy and alloy 751 specimens due to the greater strengthening in Waspaloy dominates the high cycle fatigue life under these experimental conditions.

\section{Conclusions}

Very high cycle fatigue lives of two nickel based alloys, alloy 751 and Waspaloy were evaluated at $870^{\circ} \mathrm{C}$ and microstructural evolution that occurred during exposure to the high temperature was followed as a function of fatigue cycles. Significant coarsening of $\gamma^{\prime}$ precipitate was observed in both alloys, resulting in a loss of strength as a function of exposure at $870^{\circ} \mathrm{C}$. Results from fatigue testing show that for the conditions tested, Waspaloy shows better fatigue life than alloy 751. These results are consistent with the larger static strength of Waspaloy at $870^{\circ} \mathrm{C}$ when compared to that of alloy 751. 


\section{Acknowledgments}

GM would like to acknowledge Jackie Mayotte for his help with metallography, and Paul Menchhofer for his help with microscopy, and Dr. G. R. Romanoski, Dr. Y. Yamamoto, and Dr. R. R. Unocic, and Dr. M. J. Warwick for their review of the manuscript. This research was sponsored by the U.S. Department of Energy, Assistant Secretary for Energy Efficiency and Renewable Energy, Office of Vehicle Technologies, as part of the Propulsion Materials Program. The authors would also like to acknowledge the use of the SHaRE User Facility, sponsored at Oak Ridge National Laboratory by the Division of Scientific User Facilities, Office of Basic Energy Sciences, U.S. Department of Energy.

\section{References}

1. H. Mughrabi, "Specific features and mechanisms of fatigue in the ultrahigh-cycle regime,” International Journal of Fatigue 28 (2006) 1501-1508.

2. T. Sakai, "Review and prospects for current studies on very high cycle fatigue of metallic materials for machine structural use,” Proceedings of the Fourth International Conference on Very High Cycle Fatigue (VHCF-4), Eds. J. E. Allison et al, TMS, 2007, pp. 3-12.

3. K. S. Chan, "Roles of microstructure in fatigue crack initiation," International Journal of Fatigue, 32(2010), pp. 1428-1447.

4. A. Pineau and S. D. Antolovich, "High temperature fatigue of nickel-base superalloys-A review with special emphasis on deformation modes and oxidation,” Engineering failure Analysis 16 (2009), pp. 2668-2697.

5. N. Saunders, X. Li, P. Miodownik and J. Ph. Schillé in "Proc. Symp. Materials Design Approaches and Experiences,” eds. J-C. Shao et al, TMS, Warrendale, PA, 2001, p 185197.

6. N. Saunders, M. Fahrmann and C. J. Small, in Superalloys 2000U, eds, K. A..Green, T. M. Pollock and R. D. Kissinger, TMS, Warrendale, PA, 2000, 803.

7. B. A. Lerch and N. Jayaraman, "A study of fatigue damage mechanisms in Waspaloy from 25 to $800^{\circ} \mathrm{C}$,” Materials Science and Engineering, 66 (1984), pp.151-166.

8. S. Suresh, Fatigue of Materials, Second Edition, Cambridge University Press, Cambridge, UK, 1998.

9. J. Miao, T. M. Pollock, and J. W. Jones, "Very high cycle fatigue behavior of nickelbased superalloys René 88DT at $593^{\circ} \mathrm{C}$,” Proceedings of the Fourth International Conference on Very High Cycle Fatigue (VHCF-4), Eds. J. E. Allison et al, TMS, 2007, pp. 445-450.

10. M. Oja, K. S. Ravi Chandran, and R. G. Tryon,” Orientation Imaging Microscopy of fatigue crack formation in Waspaloy: Crystallographic conditions for crack nucleation,” International Journal of Fatigue, 32 (2010), pp.551-556.

11. M. Zimmermann, C. Stoecker, and H.-J. Christ, "Effect of particle strengthening on the very high cycle fatigue behavior of two Nickel-Base alloys,” Plasticity, Failure and Fatigue in Structural Materials-from Macro to Nano: Proceedings of the Hael Mughrabi Honorary Symposium, Eds. E. Jimmy Hsia et al., TMS, 2008, pp. 63- 68.

12. C. Stoecker, M. Zimmermann, and H. -J. Christ, "Influence of prestraining on the hightemperature fatigue behaviour of polycrystalline nickel-based superalloys in the VHCF regime,” Procedia Engineering, 2 (2010), pp.1383 - 1392.

13. Y. Liu, J. J. Yu, Y. Xu, X. F. Sun, H. R. Guan, and Z. Q. Hu, "High cycle fatigue behavior of a single crystal superalloy at elevated temperature,” Materials Science and Engineering A 454-455 (2007), pp. 357-366. 